\title{
PARTICIPATORY GIS IN ACTION, A PUBLIC HEALTH INITIATIVE FROM KERALA, INDIA
}

\author{
B. Soman* \\ Achutha Menon Centre for Health Science Studies, Sree Chitra Tirunal Institute for Medical Sciences and Technology, \\ Trivandrum-11, India - bijusoman@sctimst.ac.in
}

KEY WORDS: GIS, Public health, Health surveillance, Community participation, Village women

\begin{abstract}
:
Community ownership is essential for sustainable public health initiatives. The advantages of getting active involvement of homebound village women in a public health campaign to establish community health surveillance are being reported in this paper. With the support of the local self government authorities, we had selected 120 village women, and they were given extensive training on various healthcare schemes, home based management of local ailments, leadership skills and survey techniques. Afterwards, they had been asked to share their knowledge with at least 10-15 women in their neighbourhood. This had improved their status in the neighbourhood, as more and more people started getting their advice on healthcare and social services related matters. Subsequently, they had collected the socio-demographic and morbidity details of the entire households, including the geometric coordinates (longitude and latitude) of the households and public offices. In this process, they began to use the geographic position system (GPS) machines, dismissing the myth that women are not that techno savvy, further improving their acceptability in the community. Many among them were seen proudly describing the implications of the thematic maps to the village people and line department staff in the monthly subcentre meetings. Many were offered seats in the local body elections by leading political parties, a few of them did stand in the elections and three of them had won the elections. This experience reinforces our belief that the empowerment of villagers with newer technology could be a public health tool with much wider positive implications.
\end{abstract}

\section{INTRODUCTION}

\subsection{Kerala - unique socio-political context}

This densely populated state, located in the south-west corner of India, with a population of 33.4 million spread over an area of 38,863 sq. km has many unique features.(Kannan et al. 1991) It has a better infant mortality and maternal mortality rates, higher literacy rates, higher school enrolment rates, and higher healthcare utilisation rates compared to many other Indian states.(Registrar General India 2011) Following the spirit of the $73^{\text {rd }} 74^{\text {th }}$ constitutional amendments in 1993, Kerala has enacted the Kerala Panchayat Raj act, 1994 and Kerala Municipality Act, 1994 by the then ruling right wing United democratic Front (UDF) government and the $9^{\text {th }}$ five year plan allocations were planned accordingly.(Commission 2008) The momentum of decentralised planning got intensified in 1996, when the left wing Left Democratic Front (LDF) came into power and the Kerala Sastra Sahitya Parishad(KSSP) initiated a campaign to ensure community participation in the initiative.(Elamon et al. 2004; Kannan 2000) Under the process, the Local Self Government Institutes (LSGI) were given $40 \%$ of the plan budget $\mathrm{b}$ the state governments and the Panchayats (LSGI) were free to decide upon their priorities for the next five years under some broad guidelines. Women empowerment was given major thrust in the people's campaign and one third of the LSGI seats were reserved for women, which was later increased to one half in 2009.(Joseph 2009; Kuttappan 2013)

\subsection{Athiyannur Sree Chitra (ASA) initiative}

The Sree Chitra Tinunal Institute for Medical Sciences and Technology (SCTIMST) is an institute of national importance in India, which is an autonomous institute, with a standing of a University, under the department of science and technology, Government of India. It has a biomedical unit, a super-specialty hospital and a public health unit, called the Achutha Menon Centre for Health Science Studies (AMCHSS). AMCHSS was the first public health school in India to start the Master of Public Health (MPH) program, way back in 1997. In the light of the decentralised planning process in Kerala, AMCHSS got into a pack with the Athiyannur Block Panchayat in 2004 to support the local body in their health planning. The program was named the Athiyannur Sree Chitra Action (ASA) initiative and it has the following three cardinal principles. Firstly the initiative would be driven by the community, and community would be involved in all phases of any intervention, be it service or research intervention, in the area. Secondly, there should not be any duplication; ASA initiative should supplement existing services/schemes, if not filling the critical gaps in them, rather than replacing existing services or facilities run by either public or private agencies. Thirdly AMCHSS should work in the background, providing technical inputs as and when required, and it should be the local body (the Athiynnur Block Panchayat), which should be taking the lead. The author continues to be the coordinator of the ASA initiative from its beginning in 2004 till date. Initially the block was having six Grama Panchayats (GP) in its jurisdiction, namely Venganoor, Kottukal, Vizhinjam, Athiyannur, Kanjiramkulam and Karumkulam. Later with the delimitation of the civic wards in June 2010, Vizhinjam GP was separated and incorporated into Thiruvananthapurm City Corporation, leaving a total of five GPs in Athiyannur Block Panchayat.

\subsection{The Friends of Health}

In the true spirit of participatory planning, we had a series of interactive sessions with the elected leaders of the LSGI and the officials of their line departments under the block. There were many conflicts and heated discussions when the mismatch between the kind of services that are being provided versus 
which were supposed to be provided for the community were highlighted. Both the groups were accusing each other without realising the ground realities. At the end, together we decided that there need to be a third group, mature enough to have a level headed attitude towards these matters of conflict for us to move ahead. So, a group of around ten elders, called the Friends of Health $(\mathrm{FoH})$, mostly comprised of retired teachers and government employees who had been living in the Panchayat for many years and a few political activists of all colours was formed. As they were former government employees, they knew the strengths and limitations of the government systems and were quite aware of the local needs and realities, as they were living in the area for long. So this group was equally acceptable to the doctors and other higher officials as well as the LSGI functionaries, as many of them were their teachers.

On reviewing the situation, the FoH suggested that we need to take stock of the current situation, and so requested AMCHSS do a baseline socio-demographic survey of the entire block. We offered technical support, but deferred from undertaking the survey ourselves, although it would have been much easier for the institute. We asked the community to plan and organise it. We did not want the survey to be just a mechanical enterprise to collect information from the community, instead we wanted it to be a tool for community intervention. So, rather than asking them to do this and that, we coerced them to list out what all information they need. To our surprise the FoH had come up with a comprehensive list of items that need to be included in a socio-demographic survey. We concurred with the $\mathrm{FoH}$ that in order to bring in positive change in the community, we need to reach out to the womenfolk. Although Kerala has the highest women literacy rates in India, their work participation is very low.(Moli 2004) We decided to start our activities in a phased manner, starting from the Venganoor GP with an area of 12.97 $\mathrm{sq} \mathrm{km}$.

\subsection{Women health volunteers}

With the concurrence of Panchayat members and field health workers, we identified three housebound women from each of the 19 wards of the Venganoor GP and requested them to spare a few hours a day for this task. Married women who had settled down in the area were given preference, thinking that they would stay in the locality for long, and education at least up to high school level was preferred. We called them health volunteers and were given a series of training sessions, which included understanding of common ailments in the locality, house hold management of ailments, various government schemes and services, leadership skills, survey etiquettes, etc. We got financial support from the Capacity Development for Decentralisation in Kerala (CapDecK) initiative that was supported by the Swiss Agency for Development and Corporation (SDC) to supplement the institutional allocation from SCTIMST for this purpose. We had included district level officials as well as the field level functionaries of the all important line departments like health, rural development, social welfare, agriculture and education as resource persons for these trainings. Regular fortnightly training sessions were conducted at the Community Health Centre (CHC) Vizhinjam, situated in Venganoor GP for about six months. The doctors and other staff from the local Community Health Centres(CHC) and Primary Health Centres(PHC), Integrated Child Development Services (ICDS) supervisors and Village extension workers of the rural development departments were the primary facilitators for the trainings. Volunteers were given tea, snacks and meal for the day and a travel honorarium to meet their expenses on the days of the trainings. Every month there were some practical tests, which were more for the benefits of the trainers rather than the trainees. However these should have worked as a self assessment and many incompetent ones dropped out leaving a vibrant and energetic group of 30 women.

At the end of six months, these women were asked to share their knowledge with 10-15 womenfolk in their neighbourhood. They were asked to move around in pairs for security and safety reasons and also to ensure that one person can supplement the other when they get in dialogue with the women in the community. This turned to be a real learning experience for the trainees as well as the trainers, as every other week; they had brought in lot of questions from the field that they could not answer. These were discussed with the facilitators as well as with the FoH. We concluded that in order to answer many of the questions from the local women, we need to do a sociodemographic and health census of the area. And we need to create location maps of various facilities and risk areas in the Panchayat. We then thought of doing a comprehensive geographic information system (GIS) mapping of the area. We realised that the collection of micro-location based information of the community and linking it with socio-demographic and health information should be done with caution as there could be many ethical and confidentiality issues. We decided to constitute a Community Advisory Board(CAB) to guide us on the ethical issues regarding this.

\subsection{Community Advisory Board}

GPs were given full freedom to decide upon the members of the Community Advisory Board ( $\mathrm{CAB})$. In the first $\mathrm{CAB}$, there were a couple of elected leaders, some retired officials from the locality and a doctor from outside the area, who was nominated by the Block Panchayat. The $\mathrm{CHC}$ medical officer was the convener and either the $\mathrm{CHC}$ medical officer or the ASA coordinator used to present the community intervention/research idea to the group for their concurrence, although both of them were instructed to refrain from any coercive comments. This arrangement helped a lot in harnessing community ownership, although caused minor setbacks to the researchers. For example, in order to analyse the social equity issues, researchers wanted to find out the caste of the individuals, but the $\mathrm{CAB}$ refused to include that question in the survey, claiming that it will raise many unpleasant issues to the Panchayat body.

This was the context in which we have gone for participatory GIS mapping exercise with the help of scientists from the Centre for Earth Science Studies(CESS), Thiruvananthapuram.

\section{MAPPING BY VILLAGE WOMEN}

\subsection{Village Resource Maps}

Participatory Resource Mapping had been undertaken by various agencies and local bodies in Kerala particularly after the decentralisation initiative.(Chattopadhyay et al. 1999) However in many of those exercises, educated and young men were involved rather than village women as in our case. Moreover many of the earlier programs got funding support from the local bodies or government agencies. We wanted the village health volunteers, whose primary role being health activism, to undertake the mapping exercise so that they would feel comfortable to use the maps for health planning. AMCHSS had requested the Geomatics division of the Centre for Earth Science Studies(CESS), Thiruvanthapuram for the technical expertise. They honoured our request for a nominal fee and helped us to train the village women in mapping exercise. At 
that time we were not having Geographic Position System(GPS) machines in sufficient numbers, so we went for a manual mapping exercise using guide maps and survey tapes.

Cadastral maps of the villages were obtained from the revenue department. Scientists from CESS took geo-coordinates of the salient points in the Panchayats, like major junctions, major roads, government offices, schools etc, which were used to georeference the cadastral maps. Subsequently guide maps with north arrow for each ward were created, printed and distributed to the survey teams to help them in orientation and location identification. Enlarged cadastral maps, wherein salient features like major roads and junctions were marked were printed in A1 size papers to the scale of 1:10,000 were given to the survey teams for marking the points. They had measured the distance from the nearby junction/road to the front door of the household using the survey tapes in metres and marked the point and the corresponding house identification numbers (HIN) in the enlarged and printed cadastral maps with the help of the guide maps to decide the direction of displacement. For every 10 metre in the field, one $\mathrm{mm}$ displacement was made in the paper maps. Later these geo-referenced cadastral maps were scanned and the geo-coordinates were captured manually and linked up with the corresponding household database using the HIN. This was a labour intensive work, and the volunteers were undertaking this exercise after finishing the household survey, using a structured questionnaire spreading around four pages. The volunteers were moving in groups of two and three and used to take quite a lot of time in each locality. Usually by the end of the interview, when they start to measure the distance from the road/junction, the entire community members would have come forward to help them in holding the tape and other amenities. In order to cross check the validity of the information, we had collected the survey number of the property and the nearest road and junction in the survey format. However many households refused to share the survey number of their property, especially those near the Vizhinjam harbour fearing that their property would be taken over by the government. Therefore the survey number was omitted from the survey proforma afterwards, when we had up-scaled the survey to other GPs. The initial maps were created in the modified Everest datum in the scale of 1:12,500 using the Arc GIS software by the scientist at CESS. (Fig.1) Separate maps were produced and printed out in A1 sheets for each of the eight health subcentres in the Panchayats. It took more than six months to complete 8925 households by 15 teams of volunteers, as the women were doing the job during their free time.

The Junior Public Health Nurses (JPHNs) who were supervising the survey by the women volunteers were thrilled when they could see the geo-referenced maps of the entire households in their jurisdiction hanging in the walls of their subcentres. A standalone decision support system was created by CESS in Map Server software and that was installed in the Venganoor GP office. Moreover, during the monthly sub-centre meetings, which were chaired by the elected leaders, the project team from AMCHSS would show the corresponding maps on laptops enabling them to get more insights into their health issues. For instance, in one of such meetings, when the concern for the waning numbers of beneficiary children for vaccination was brought in, one of our village volunteers suggested to conduct outreach immunisation sessions in a couple of distant colonies in the region. She was pointing the map to substantiate her logic, which was accepted and the vaccination rates improved in the subsequent months.

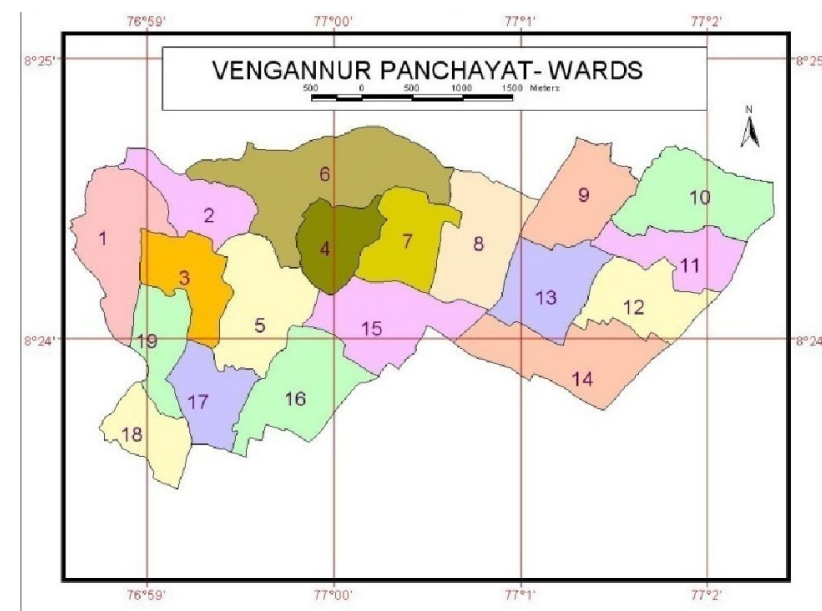

Figure 1. Geo-referenced map of the first GP

The volunteers had became famous in their locality, as more and more people started getting their advice on health care options and other government schemes. They had also benefitted economically from the survey honorarium, although nominal this was a surprise gift to these homebound village women, who were solely depending on their husband's income. The 2009 amendments of the Kerala Panchayat Raj act had got through at that time and the reserved seats for women were raised from the then existing $30 \%$ to $50 \%$. Political parties were on look out for potential women candidates, and many leading parties have offered seats to many of our volunteers. Three of our women volunteers stood for the 2010 local body elections and two of them won the election from this GP alone. This has given much local acclaim to the ASA initiative and more and more GPs started demanding to initiate such programs in their area

\subsection{Up-scaling using better technology}

We got funding support under the Women Component Plan(WCP) for Department of Science \& Technology (DST), Government of India(GoI) to upscale the exercise to other four panchayats; by that time the Vizhinjam GP was separated from the Athiyannur Block leaving only five GPs in the Block Panchayat. Similar exercises were done in those GPs with slight modification. AMCHSS had procured 10 GPS units (Garmin eTrex Legend) for another research project, which had gotten completed and the GPS machines were left with the ASA coordinator. We planned to use GPS machines for the survey in these Panchayats. There were huge rush to get enrolled as health volunteers in these GPs. Keeping our experience in Vengaoor GP in mind, we had enrolled 204 volunteers from the 68 wards, for the trainings, and out of them 90 had endured all the stringent training processes and were ready for the work. Here the trainings were a lot more organised and our initial volunteers had been involved in the training program as peer educators. Instead of paper based maps and survey tapes, we trained them to use GPS machines. Due to logistic reasons and the paucity of machines, GPS surveys were done afterwards, again by selected women volunteers. The initial team will leave a barcode with unique house ID pasted in each household, which would be noted and entered by the GPS survey team along with the corresponding waypoints and geo-coordinates.

By this time the geo-spatial resources at AMCHSS had strengthened and we started using the free and open source software, the QGIS for the initiative. We could complete the 
entire exercise covering 26,536 households in 18 months. (Fig.2)

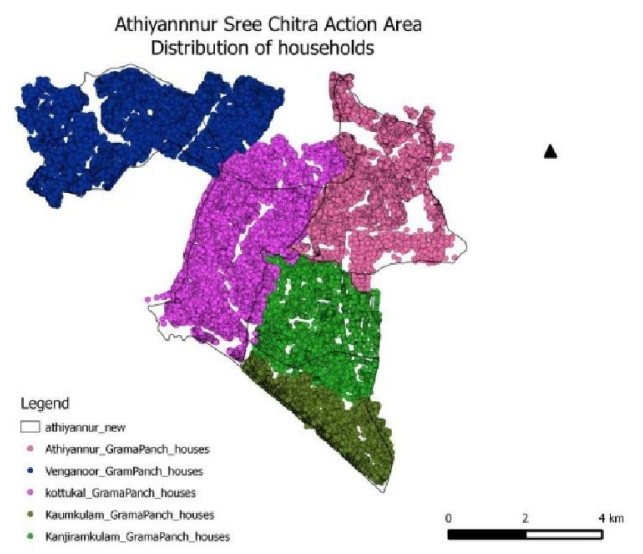

Figure 2. Spatial distribution of 35,461 households in ASA area

The ASA initiative had effected tremendous appreciation in the community. Panchayat people started looking at the thematic maps displayed in their Panchayat offices and health centres before taking major decisions on water supply schemes and other service sector schemes. A decision support system was developed with the help of informatics people and got installed in the computers in the CHC and PHCs.(Fig.3)

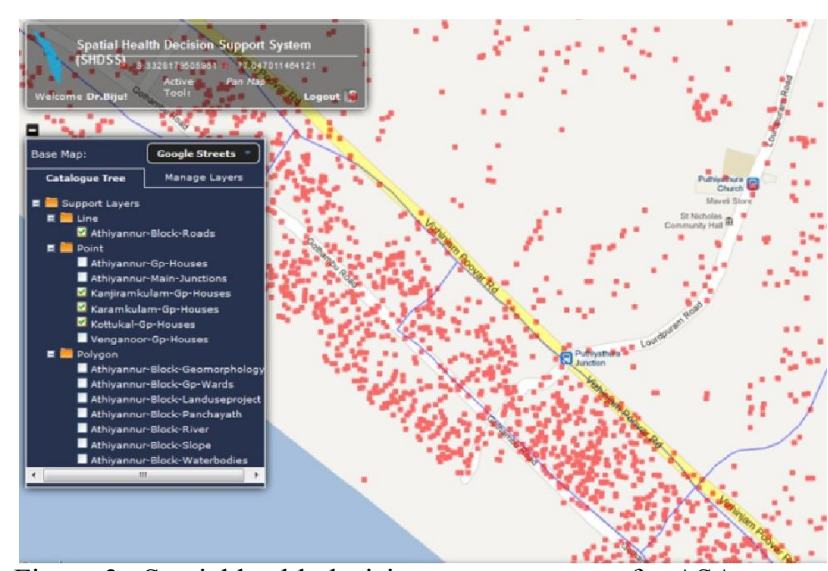

Figure 3. Spatial health decision support system for ASA area

\section{GIS FOR POSITIVE SOCIAL CHANGE}

The incorporation of participatory GIS mapping, by the village women in the ASA initiative, had brought in many positive dividends in public health scenario in Kerala.

\subsection{Pioneering effort of health GIS in Kerala}

GIS had been used by the urban planning agencies for long. However the ASA initiative was one of the first attempts to link health data, by way of linking the morbidity and mortality events with their spatial pattern for local action. For example during the dengue epidemic in 2003-04 in Kerala, more cases occurred in areas of Athiyannur Block Panchayat, which were having shortage of drinking water.(Fig.4) Those areas with relatively less open wells and inadequate piped water supply got affected, which lead to the hypothesis that household water storage utensils could be the potential breeding places for the Aedes mosquitoes that spread dengue and chikungunya diseases.(Anish et al. 2011) This substantiates the argument that health interventions need not always be medical, lay people and policy makers can avert many potential health hazards. In another recent unpublished analysis it was observed that more dengue mortality occurred in the eastern high lands of the Thiruvananthapuram district, which has less medical facilities.

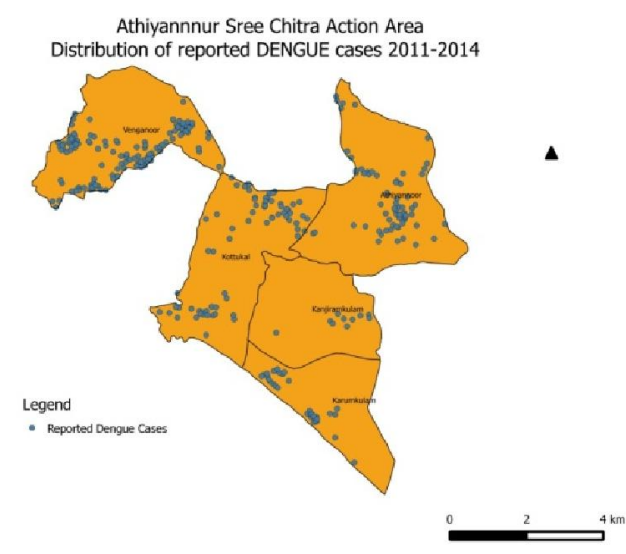

Fig. 4 Distribution of reported dengue cases in ASA area

\subsection{Women empowerment in true sense}

It is common to offer training sessions for women to catch up with men in their skills and knowledge. Here we had gone beyond the usual by training village women on a totally new and challenging technology, the GIS mapping and its use, which they could teach the men folk in the community. The contextual advantage of the thrust for women empowerment in the decentralisation campaign had complemented ASA initiative by way of opening up new avenues for women to excel. Inclusion of leadership building and gender equity sessions in our trainings had helped the volunteers to tap these opportunities. We also got disillusioned of the myth that women cannot handle technology through this exercise. This exercise also motivated the state government to provide computer tablets to the field level workers as a part of the upcoming eHealth project.

\subsection{Highlights need for trans-disciplinary initiatives}

Health of the community is such an important issue that can not be solely left to a few doctors or the medical establishment. Much health benefits can be brought in through timely interventions based on common sense approach. Judicious use of newer technologies like GIS for health by community stakeholders would help to mitigate many a public health scourges in the community. It is not easier for people from different professions to work together, as this is restricted not only by the profession-specific jargons but often the working pattern or work culture could be different. So it is easier to tell than to prove to work together; which should be done in a mutually respectful way. Here in ASA initiative we could prove that health professionals could work seamlessly with local leaders, informatics professionals, GIS scientists and the village women for the cause of community's well being.

We have been involving our postgraduate students, from public health, super specialty and engineering disciplines in these initiatives to work together with the community with the hope that the philosophy of working together in a participatory way will catch on. 


\section{ACKNOWLEDGEMENTS}

I owe my gratitude to the people of the Athiyannur Block Panchayat and the authorities of SCTIMST, who have been supporting the ASA initiative till date. I thank the SDCCapDecK, WCP(DST-GoI) and SCTIMST for the financial support during crucial phases of the initiative. I also use this opportunity to acknowledge the following persons, who had helped me in the initiative at various stages.

Dr Manju R Nair, Scientist C, AMCHSS, SCTIMST

Mr Sujith PS, Research Associate, AMCHSS, SCTIMST

Mr Rajesh K, Field Coordinator, AMCHSS, SCTIMST

Sr Chandrika R, Field Coordinator, AMCHSS, SCTIMST

Mr Jayaprasad BK, Scientist in charge, Geomatics Lab, Centre

for Earth Science Studies(CESS), Thiruvananthapuram

Prof. Sankara Sarma P, Biostatistician, AMCHSS, SCTIMST

\section{REFERENCES}

Anish, T., Vijayakumar, K. and Leela, I.A.K. 2011. Domestic and Environmental Factors of Chikungunya-affected Families in Thiruvananthapuram (Rural) District of Kerala, India. Journal of Global Infectious Diseases 3(1), pp. 32-36.

Chattopadhyay, S., P Krishna, Kumar and K, Rajallekshmi 1999. Panchayat Resource Mapping to Panchayat -level Planning in Kerala: An Analytical study.

Commission, I.P. 2008. Kerala Development Report. Academic Foundation.

Elamon, J., Franke, R.W. and Ekbal, B. 2004. Decentralization of health services: the Kerala People's Campaign. International journal of health services: planning, administration, evaluation 34(4), pp. 681-708.

Joseph, T.M. 2009. Decentralised governance and development. New Delhi: Deep \& Deep Publications.

Kannan, K. 2000.People's planning, Kerala's dilemma. Seminar (485).http://www.indiaseminar.com/2000/485/485\%20kannan.h tm (14 Nov. 2014).

Kannan, K.P., Thankappan, K.R., Ramankutty, V. and Aravindan, K.P. 1991. Kerala: a unique model of development. Health Millions 17(5), pp. 30-3.

Kuttappan, M. 2013. Self Reliance; 20 years of experience. Kerala Calling. http://www.kerala.gov.in/ docs/publication/2013/kc/june_13/14.pdf.(14 Nov.2014)

Moli, G. 2004. Labour force in Inda; the gender gap. Samyukta 4(2), pp. 53-6.

Registrar General India 2011. Census of India 2011. New Delhi: Office of Registrar General \& Census Commissioner (Government of India). 